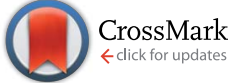

Cite this: RSC Adv., 2016, 6, 38769

Received 25th February 2016 Accepted 31st March 2016

DOI: $10.1039 / c 6 r a 05037 a$

www.rsc.org/advances

\section{Hydrogen production from buffer-free anaerobic fermentation liquid of waste activated sludge using microbial electrolysis system $\uparrow$}

\author{
Weiwei Cai, ${ }^{a}$ Wenzong Liu, ${ }^{\text {tb }}$ Dan Cuil and Aijie Wang ${ }^{\text {*ab }}$
}

Anaerobic fermentation liquid from waste activated sludge with a rich content of organics and phosphate ions is a promising source of carbon and electrolytes for MECs. The effects of three different electrolytes, including phosphate buffer solution (PBS), bicarbonate buffer solution (BBS), and sodium chloride ( $\mathrm{NaCl}$ ), on the performance of an MEC fed with sludge fermentation liquid (SFL) were compared under conditions of similar conductivity. The production yield of hydrogen was $0.92 \mathrm{~mL} \mathrm{mg}^{-1} \mathrm{COD}$ in an $\mathrm{MEC}$ with $\mathrm{NaCl}$, which performed similarly with yields of $1.03 \mathrm{~mL} \mathrm{mg}^{-1}$ with BBS and $1.04 \mathrm{~mL}$ $\mathrm{mg}^{-1}$ with PBS. The COD removal efficiencies exceeded $50 \%$ in all three groups. Although the energy efficiency of $108 \%$ with $\mathrm{NaCl}$ was lower than that with PBS (121\%), the self-buffering system had advantages regarding cost and environment-friendly application over both PBS and BBS. Comparable performance could be obtained in an MEC with $\mathrm{NaCl}$ by adjusting the conductivity using SFL as a carbon source and buffer solution.

\section{Introduction}

In recent years, the biological production of $\mathrm{H}_{2}$ via a microbial electrolysis cell (MEC) has emerged as one of the most attractive technologies because of its high yield and impressive production rate. In an MEC, the microbial community at the anode could oxidize organic substrates such as glucose and acetate and transfer electrons to the cathode for the purposes of the hydrogen evolution reaction. ${ }^{1}$ Previous research has shown that hydrogen production rates could be increased by modifying the electrode spacing, anode type, anode arrangement, catholyte, ionic strength of the solution, electrode material and buffer solution. ${ }^{2-6}$ Among these methods, the selection of the feedstock and buffer solution has attracted a lot of attention.

${ }^{a}$ State Key Laboratory of Urban Water Resources and Environments, Harbin Institute of Technology, Harbin 150090, China.E-mail: waj0578@hit.edu.cn

${ }^{b}$ Research Center for Eco-Environmental Sciences, Chinese Academy of Sciences, Beijing 100085, PR China.E-mail: wzliu@rcees.ac.cn

$\uparrow$ Electronic supplementary information (ESI) available. See DOI: 10.1039/c6ra05037a
As the main form of solid waste produced in wastewater treatment processes, waste activated sludge is increasingly attractive for utilization as a cheap but valuable energy source. Abundant organics, including carbohydrates, proteins and short-chain fatty acids, are accumulated in fermented waste activated sludge, which is an ideal feedstock for MECs. ${ }^{7-9}$ Moreover, carbohydrates, proteins and their acidification products in sludge fermentation liquid (SFL) can be utilized in a cascade for the generation of hydrogen. ${ }^{10}$ However, the utilization of a buffer solution is still a critical factor for the operation of MECs when SFL is used as a substrate. Phosphate buffer solution (PBS), as an efficient buffer solution, has been extensively used to reduce the variation in $\mathrm{pH}$ in MECs, because a lower or higher $\mathrm{pH}$ resulting from substrate fermentation has an adverse effect on exoelectrogens and the production of $\mathrm{H}_{2} \cdot{ }^{11-14}$ However, PBS is hard to recover from the effluent and can easily cause secondary pollution after being discharged. Alternatively, bicarbonate buffer solution (BBS) is another good, low-cost choice for the control of $\mathrm{pH}$ in MECs. ${ }^{15}$ The external addition of sodium bicarbonate is essential, as the concentration of self-generated $\mathrm{CO}_{2}$ in MECs is too low to prevent the $\mathrm{pH}$ from increasing. ${ }^{15}$ However, the addition of reagents such as PBS or BBS brings about extra cost for the production of biohydrogen. Notably, SFL contains not only a rich content of organics but also certain ions (such as $\mathrm{NH}_{4}{ }^{+}$and $\mathrm{PO}_{4}{ }^{3-}$ ), ${ }^{16,17}$ which could be used as a substitute to enable the maintenance of $\mathrm{pH}$ cost-effectively. Hence, SFL can be fed into MECs as a feedstock and buffer solution simultaneously, which is highly meaningful for potential applications, although there has been a lack of studies.

To highlight the advantage of SFL as a self-buffering substrate, the effects of three different buffer solutions, namely, PBS, BBS, and SFL, which have similar conductivities, on the performance of an MEC were compared. Comparable performance in the production yield of hydrogen, degradation of organics and operation of the MEC was obtained with $\mathrm{NaCl}$ by only adjusting the conductivity of the electrolyte, which indicates the potential advantage of using SFL alone to 
maintain the $\mathrm{pH}$ conditions required for microbial activity and the hydrogen evolution reaction.

\section{Materials and methods}

\subsection{Waste activated sludge characteristics and fermentation set-up}

Waste activated sludge was collected from the second settling tank of the Taiping wastewater treatment plant in Harbin, China. The waste activated sludge was concentrated at room temperature $\left(25^{\circ} \mathrm{C}\right)$ for $24 \mathrm{~h}$. The main characteristics of the concentrated sludge are listed in Table 1.

Waste activated sludge $(900 \mathrm{~mL})$ was inoculated with $100 \mathrm{~mL}$ activated sludge collected from a UASB reactor in Taiping wastewater treatment plant in $1100 \mathrm{~mL}$ serum bottles (Sichuan Shubo (Group) Co., China). The waste activated sludge was treated by thermophilic microaerobic bacteria at a controlled temperature of $55{ }^{\circ} \mathrm{C}$, which was obtained by heating with a water bath, and dissolved oxygen $\left(\leq 0.5 \mathrm{mg} \mathrm{L}^{-1}\right)$ was regulated via continuous aeration. The concentration of stable VFAs reached $1190 \mathrm{mg} \mathrm{L}^{-1}$, which contained $\sim 725 \mathrm{mg} \mathrm{L}^{-1}$ acetate as the main product after 8 days. The pretreatment sludge was centrifuged and saved as the fermentation liquid for the production of hydrogen in an MEC.

\subsection{Construction and operation of single-chamber MEC}

The biohydrogen process was conducted using a singlechamber MEC, which was made of polycarbonate as previously described..$^{13}$ A graphite brush anode (25 mm diameter, 25 mm length, $0.22 \mathrm{~m}^{2}$ surface area; fiber type: PANEX $33160 \mathrm{~K}$, Zoltek) was soaked in acetone for $24 \mathrm{~h}$ and heated in a muffle furnace at $450{ }^{\circ} \mathrm{C}$ for $30 \mathrm{~min} .{ }^{18}$ Ten single-chamber MECs were constructed and inoculated with activated sludge simultaneously. All reactors were supplied with a fixed voltage of $0.7 \mathrm{~V}$. A mixed solution was prepared as follows: sodium acetate $(1 \mathrm{~g}$ $\left.\mathrm{L}^{-1}\right), 50 \mathrm{mM}$ PBS $\left(\mathrm{Na}_{2} \mathrm{HPO}_{4},\left(4.58 \mathrm{~g} \mathrm{~L}^{-1}\right)\right.$ and $\mathrm{NaH}_{2} \mathrm{PO}_{4} \cdot \mathrm{H}_{2} \mathrm{O}$ $\left.\left(2.45 \mathrm{~g} \mathrm{~L}^{-1}\right), \mathrm{pH}=7.0\right)$ and nutrient solution $\left(\mathrm{NH}_{4} \mathrm{Cl}\left(0.31 \mathrm{~g} \mathrm{~L}^{-1}\right)\right.$, $\mathrm{KCl}\left(0.13 \mathrm{~g} \mathrm{~L}^{-1}\right)$, and trace nutrient medium). When all of the reactors displayed similar stable performance, the substrate was replaced by different SFL solutions in three electrolytic systems (electrolyte solution: SFL 50 : 50 (v/v)). Reactors 1-3

Table 1 Main characteristics of waste activated sludge

\begin{tabular}{lll}
\hline Parameter & $\begin{array}{l}\text { Concentration } \\
\left(\mathrm{mg} \mathrm{L}^{-1}\right)\end{array}$ & $\begin{array}{l}\text { Pretreatment } \\
\left(\mathrm{mg} \mathrm{L}^{-1}\right)\end{array}$ \\
\hline VSS & 14000 & - \\
TSS & 30000 & - \\
SCOD & 546 & 3333 \\
Total VFAs (as COD) & 371 & 1632 \\
Carbohydrate (as COD) & 59 & 298 \\
Protein (as COD) $_{\mathrm{PO}_{4}{ }^{3-} \text {-P }}$ & 105 & 948 \\
$\mathrm{NH}_{4}{ }^{-}$-N & 90 & 660 \\
pH & 144 & 605 \\
TCOD & 6.72 & 6.95 \\
& 11739 & -
\end{tabular}

were buffered with $50 \mathrm{mM}$ PBS $(\mathrm{pH}=6.91$ as prepared, conductivity of $\left.\sim 6.71 \mathrm{mS} \mathrm{cm}^{-1}\right)$. Reactors $4-6$ were fed with 80 mM BBS (6.71 g L ${ }^{-1} \mathrm{NaHCO}_{3}, 0.31 \mathrm{~g} \mathrm{~L}^{-1} \mathrm{NH}_{4} \mathrm{Cl}, 0.05 \mathrm{~g} \mathrm{~L}^{-1}$ $\mathrm{Na}_{2} \mathrm{HPO}_{4}, 0.03 \mathrm{~g} \mathrm{~L}^{-1} \mathrm{NaH}_{2} \mathrm{PO}_{4} \cdot \mathrm{H}_{2} \mathrm{O}, \mathrm{pH}=8.1$ as prepared), which had a similar conductivity $\left(\sim 6.63 \mathrm{mS} \mathrm{cm}^{-1}\right)$ to that of PBS. The remaining three reactors 7-9 used $\mathrm{NaCl}$ solution (3.6 $\mathrm{g}$ $\left.\mathrm{L}^{-1} \mathrm{NaCl}, \mathrm{pH}=7.07\right)$ with $\mathrm{SFL}$ as the substrate and its conductivity reached $6.58 \mathrm{mS} \mathrm{cm} \mathrm{cm}^{-1}$. The final reactor was operated as a control reactor with original SFL but without any additional reagents. All MECs were operated in a $24 \mathrm{~h}$ batch mode at room temperature $\left(22 \pm 2{ }^{\circ} \mathrm{C}\right)$.

\subsection{Analysis and calculation}

To analyze the composition of volatile fatty acids (VFAs), an Agilent gas chromatograph (GC) was utilized. ${ }^{19}$ The total content of VFAs was calculated as the sum of the measured contents of acetate, propionate, n-butyrate, isobutyrate, $n$-valerate and isovalerate. The determinations of soluble chemical oxygen demand (SCOD), carbohydrate and protein were the same as described in our previous publication. ${ }^{20}$ Voltage and current were recorded using a multimeter (model 2700, Keithley Instruments, USA) every $10 \mathrm{~min}$. Gases (hydrogen, carbon dioxide, methane) were analyzed using a GC (Fuli GC9790II, Zhejiang Analytical Instrument Inc., China). ${ }^{21}$ The $\mathrm{pH}$ and conductivity were measured using a $\mathrm{pH}$ meter (PHS3C, Yangguang Laboratory Apparatus Co., Ltd.) and Bante950 conductivity/TDS/salinity/resistivity meter (Shanghai Bante Instruments Co., Ltd), respectively.

The coulombic efficiency related to anode performance was calculated according to the ratio of $Q_{\mathrm{c}}$ to $Q_{\mathrm{T}}$, where $Q_{\mathrm{c}}$ represents coulombs of current calculated by the equation $Q=I t$. The hydrogen recovery efficiency at the cathode $\left(R_{\text {cat }}\right)$ was calculated using the equation $R_{\text {cat }}=Q_{\mathrm{H}} / Q_{\mathrm{c}} \times 100 \%$, where $Q_{\mathrm{H}}=$ $2 V_{\text {Hydrogen }} / V_{\mathrm{m}} \times F, Q_{\mathrm{H}}$ represents the coulombs of electrons used to produce hydrogen, $F$ is Faraday's constant $(96485 \mathrm{C}$ $\left.\mathrm{mol}^{-1}\right), V_{\mathrm{H}}$ is the volume of hydrogen and $V_{\mathrm{m}}$ is the molar volume of a gas $\left(22.4 \mathrm{~L} \mathrm{~mol}^{-1}\right)$. Energy efficiency was defined as the ratio of $W_{\mathrm{H}}$ to $W_{\text {input }}$, where $W_{\mathrm{H}}$ is the heat of combustion of the hydrogen produced and $W_{\text {input }}$ is the electricity input. All equations were calculated based on our previous study ${ }^{22,23}$ under standard conditions.

\section{Results and discussion}

\subsection{Start-up of parallel MECs}

Nine reactors were operated for 10 days with acetate as the carbon source to achieve similar performance. Ultimately, the coulombic efficiency of the nine reactors was maintained at 98.1 $\pm 11 \%$. The energy efficiency of hydrogen production reached an average of $152 \%$ at an applied voltage of $0.7 \mathrm{~V}$.

Obviously, the coulombic efficiency indicates that the microbes at the anode consumed almost all the acetate and transferred electrons to the electrode. Moreover, in the presence of homoacetogens in a single-chamber MEC, ${ }^{24}$ hydrogen could be converted into acetate, which could be further consumed by exoelectrogens to generate current at the anode. This pathway 
has been researched in previous studies and named the hydrogen recycle. The hydrogen recycle in a single microbial electrolysis cell led to a higher value of coulombic efficiency of over $100 \%$ and low cathodic conversion efficiency and energy efficiency, although there was no apparent effect on the yield of hydrogen. ${ }^{25}$ The hydrogen recycle in MECs will become a key factor in the future.

\subsection{Degradation of SFL fraction}

After the pretreatment by thermophilic aerobic digestion of waste activated sludge, SCOD increased to $\sim 3333.3 \mathrm{mg} \mathrm{L}^{-1}$ and the contents of saccharides, proteins and VFAs were $\sim 279 \mathrm{mg}$ $\mathrm{L}^{-1}, \sim 632 \mathrm{mg} \mathrm{L}^{-1}$ and $\sim 1190 \mathrm{mg} \mathrm{L}^{-1}$, respectively. VFAs and saccharides were almost depleted in a $24 \mathrm{~h}$ batch run, but the content of proteins decreased slightly in all reactors. The maximum rate of degradation of VFAs was $76 \%$ with BBS. The SCOD removal rate was $49 \%$ with PBS, $48 \%$ with BBS and $47 \%$ with NaCl. Similar SCOD removal rates were achieved with different buffer systems (shown in Fig. 1). In contrast, the value for the control group without an externally added solution was $\sim 35 \%$ (Fig. S1 $\dagger$ ), which was lower than those of the others.

Liu et $a l .{ }^{9}$ used SFL as a substrate for an MEC and obtained an SCOD removal rate of $\sim 60 \%$ at an SCOD of $3228.9 \mathrm{mg} \mathrm{L}^{-1}$ and a conductivity of $8.17 \mathrm{mS} \mathrm{cm}^{-1}$ in a $48 \mathrm{~h}$ batch run. In this experiment, $\sim 35 \%$ SCOD removal rate was achieved at 3333.3 $\mathrm{mg} \mathrm{L^{-1 }}$ SCOD and a conductivity of $3.53 \mathrm{mS} \mathrm{cm}^{-1}$ in a $24 \mathrm{~h}$ batch run. An SCOD removal rate of $\sim 49 \%$ was achieved with SFL diluted twofold with PBS, of which the conductivity was $\sim 5.1 \mathrm{mS} \mathrm{cm}^{-1}$. Similar values $(\sim 48 \%$ and $\sim 47 \%)$ were obtained with $\mathrm{BBS}$ and $\mathrm{NaCl}$, of which the conductivity was $\sim 5.06 \mathrm{mS}$ $\mathrm{cm}^{-1}$. Obviously, variations in conductivity are an important factor for the COD removal rate in MECs. According to a comparison of the effect of different buffer solutions at similar conductivities, the consumption of the SCOD fraction displayed no sharp increase or decrease. The addition of $\mathrm{NaCl}$ as an ionic compound to increase conductivity also achieved similar SCOD degradation.

During a 24 hour batch run, VFAs were extensively consumed by microbes at the anode in the MEC. Moreover, acetate was first depleted with a removal rate of $\sim 80 \%$ in all different buffer

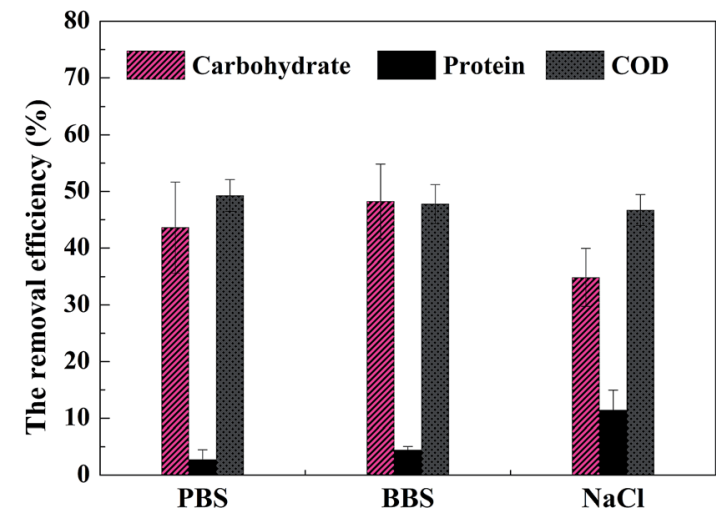

Fig. 1 Removal efficiency of individual fractions in SFL with MECs. solutions. The degradation of isovalerate in different conditions displayed a marked difference: degradation rates of $42 \%$ and $39 \%$ were achieved in PBS and $\mathrm{NaCl}$, respectively, but the value reached $\sim 91 \%$ with BBS as the buffer solution. The propionate removal rate was approximately $52 \%$ in all three situations. Some $\sim 68 \%$ of $n$-butyrate underwent reduction and conversion to electrons by exoelectrogens. The isobutyrate removal rates were $\sim 68 \%$ and $\sim 74 \%$ in $\mathrm{PBS}$ and BBS, respectively, but a removal rate of only $51 \%$ was achieved in $\mathrm{NaCl}$. The amount of $n$-valerate underwent no evident change in all the MECs (shown in Fig. 2).

The results demonstrated that different fractions of VFAs can be used in sequence by the microbial community at the anode. The degradation rates of VFAs were shown to be in the order acetate $>$ isobutyrate $>n$-butyrate $>$ propionate $>$ isovalerate $>n$-valerate in $\mathrm{PBS}$ and $\mathrm{NaCl}$. Interestingly, the distinction between BBS and PBS or NaCl was that the degradation rate of isovalerate rose to $\sim 91 \%$, which was higher than that of acetate: the degradation rates were in the order isovalerate $>$ acetate $>$ isobutyrate $>n$-butyrate $>$ propionate $>n$ valerate. The degradation reaction of isovalerate, $\mathrm{CH}_{3}\left(\mathrm{CHCH}_{3}\right)$ $\mathrm{CH}_{2} \mathrm{COOH}+\mathrm{CO}_{2}+2 \mathrm{H}_{2} \mathrm{O} \rightarrow 3 \mathrm{CH}_{3} \mathrm{COOH}+\mathrm{H}_{2}$, indicated that the absence of bicarbonate could boost the role of bacteria that consumed isovalerate. ${ }^{26,27}$ With respect to the addition of bicarbonate to the MEC, this was sufficient to supply enough $\mathrm{CO}_{2}$ to produce three molecules of acetate from each isovalerate molecule, which could contribute to the higher removal efficiency of isovalerate compared with the other experimental results for PBS and $\mathrm{NaCl}$. However, further explanations of the mechanism and pathway would be investigated in our next study.

\subsection{Performance of MECs}

In the 24 hour batch run, the current declined to less than $1 \mathrm{~mA}$ in all reactors. The production of hydrogen varied little in all reactors with the different buffer solutions. Greater production of hydrogen (1.04 $\left.\mathrm{mL} \mathrm{mg}^{-1} \mathrm{COD}\right)$ was achieved with PBS solution compared with the values of $1.03 \mathrm{~mL} \mathrm{mg}^{-1}$ and $0.92 \mathrm{~mL} \mathrm{mg}^{-1}$ that were achieved with BBS and $\mathrm{NaCl}$, respectively. Energy efficiency values of over $100 \%$ were obtained with all reactors; these

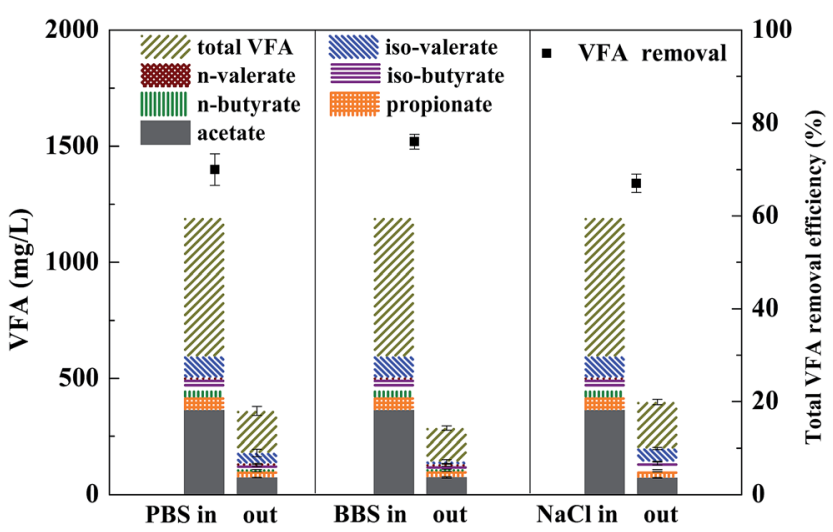

Fig. 2 Variations in content of VFAs in the effluent from MECs. 
reached a maximum value of $121 \%$ with PBS compared with $104 \%$ and $108 \%$ of BBS and $\mathrm{NaCl}$, respectively. The hydrogen recovery efficiency at the cathode $\left(R_{\text {cat }}\right)$ was low for all reactors, while reactors with BBS achieved the lowest value of $R_{\text {cat }}$, which was only $50 \%$. The value of $R_{\text {cat }}$ for reactors with PBS was close to $60 \%$ and a value of $53 \%$ was obtained with $\mathrm{NaCl}$ instead of buffer solution (shown in Fig. 3).

The coulombic efficiency of the MECs was highest in the experiments with BBS, exceeding $160 \%$, which indicated that sodium carbonate may enhance the hydrogen recycle in the chamber. Simultaneously, a lower hydrogen recovery rate at the cathode and lower energy efficiency were achieved (49\% hydrogen recovery and $104 \%$ energy efficiency). Lee et al. ${ }^{25}$ suggested that higher coulombic efficiency may lead to passive effects in a single-chamber MEC, because higher current will increase the ohmic energy loss and require a higher applied voltage for the same hydrogen production rate. PBS as a commonly used buffer solution stabilized the $\mathrm{pH}$ and led to greater production of hydrogen and energy efficiency, but created phosphate effluent. In contrast, SFL as the buffer solution in MECs displayed similar performance to PBS or BBS. Considering that the complex components of sludge fermentation liquid could result in variations in the $\mathrm{pH}$ value, this could further affect the activity of the microbial community at the anode. Therefore, the $\mathrm{pH}$ value was measured every four hours. As shown in Fig. 4, it was obvious that the $\mathrm{pH}$ value was stable during batch operation of MECs (between 6 and 8 ). The $\mathrm{pH}$ of the catholyte $(5,7,9)$ displayed similar behavior with a constant applied voltage in a previous study, ${ }^{28}$ which suggested that variations in the $\mathrm{pH}$ value were acceptable in this study. Moreover, although different buffer solutions were used to avoid $\mathrm{pH}$ shock as a result of depletion of protons during the hydrogen evolution reaction, a similar variation in the $\mathrm{pH}$ value was observed, which suggested that the effect of the buffer solution on the performance of MECs was negligible. The addition of $\mathrm{NaCl}$ increased the conductivity compared with that of the original sludge. Low conductivity will increase resistance and impede electron transfer in MECs.

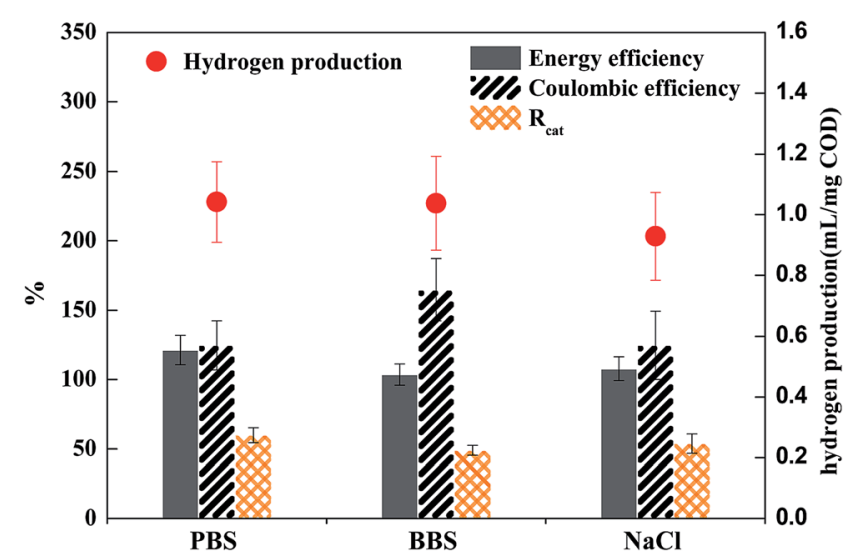

Fig. 3 Overall performance of MECs.

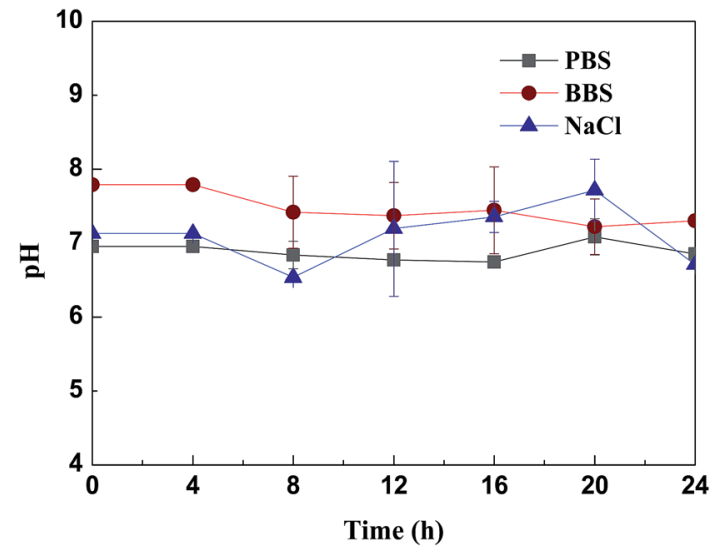

Fig. 4 Variations in $\mathrm{pH}$ with different buffer solutions.

\section{Conclusion}

Fermentation liquid from an anaerobic sludge process was successfully used as a substrate as well as an electrolyte in an MEC for the hydrogen evolution reaction without limiting effects on the hydrogen production rate or energy efficiency when $\mathrm{NaCl}$ was supplemented. The consumption of VFAs reached $\sim 80 \%$ with different buffer solutions, whereas lower SCOD removal rates were achieved when restricted by lower conductivity. Hence, the obstacle of low conductivity should be addressed for MECs. This study indicated a potential application for microbial electrolysis cells coupled with anaerobic digestion with no requirement for an external buffer solution.

\section{Acknowledgements}

This research was supported by the following grants: National Science Foundation for Distinguished Young Scholars (Grant No. 51225802), National Natural Science Foundation of China (NSFC, No. 51578534), "Hundred Talents Program" of the Chinese Academy of Sciences, Project 135 of the Chinese Academy of Sciences (No. YSW2013B06), and by the Sino-EU International S\&T cooperation program (No. S2015GR1012).

\section{References}

1 A. W. Jeremiasse, H. V. M. Hamelers, M. Saakes and C. J. N. Buisman, Int. J. Hydrogen Energy, 2010, 35, 1271612723.

2 S. Cheng and B. E. Logan, Bioresour. Technol., 2011, 102, 3571-3574.

3 S. Hays, F. Zhang and B. E. Logan, J. Power Sources, 2011, 196, 8293-8300.

4 D.-W. Liang, S.-K. Peng, S.-F. Lu, Y.-Y. Liu, F. Lan and Y. Xiang, Bioresour. Technol., 2011, 102, 10881-10885.

5 S. V. Mohan, R. Saravanan, S. V. Raghavulu, G. Mohanakrishna and P. Sarma, Bioresour. Technol., 2008, 99, 596-603.

6 T. H. Sleutels, H. V. Hamelers, R. A. Rozendal and C. J. Buisman, Int. J. Hydrogen Energy, 2009, 34, 3612-3620. 
7 E. Lalaurette, S. Thammannagowda, A. Mohagheghi, P.-C. Maness and B. E. Logan, Int. J. Hydrogen Energy, 2009, 34, 6201-6210.

8 L. Lu, N. Ren, D. Xing and B. E. Logan, Biosens. Bioelectron., 2009, 24, 3055-3060.

9 W. Liu, S. Huang, A. Zhou, G. Zhou, N. Ren, A. Wang and G. Zhuang, Int. J. Hydrogen Energy, 2012, 37(18), 1385913864.

10 L. Lu, D. Xing, B. Liu and N. Ren, Water Res., 2012, 46, 10151026.

11 Y. Yuan, B. Zhao, S. Zhou, S. Zhong and L. Zhuang, Bioresour. Technol., 2011, 102, 6887-6891.

12 Z. He, Y. Huang, A. K. Manohar and F. Mansfeld, Bioelectrochemistry, 2008, 74, 78-82.

13 D. Call and B. E. Logan, Environ. Sci. Technol., 2008, 42, 3401-3406.

14 D. F. Call, M. D. Merrill and B. E. Logan, Environ. Sci. Technol., 2009, 43, 2179-2183.

15 Y. Fan, H. Hu and H. Liu, Environ. Sci. Technol., 2007, 41, 8154-8158.

16 A. Tiehm, K. Nickel, M. Zellhorn and U. Neis, Water Res., 2001, 35, 2003-2009.

17 F. Fischer, C. Bastian, M. Happe, E. Mabillard and N. Schmidt, Bioresour. Technol., 2011, 102, 5824-5830.
18 X. Wang, S. Cheng, Y. Feng, M. D. Merrill, T. Saito and B. E. Logan, Environ. Sci. Technol., 2009, 43, 6870-6874.

19 A. Zhou, C. Yang, Z. Guo, Y. Hou, W. Liu and A. Wang, Biochem. Eng. J., 2013, 77, 240-245.

20 A. Zhou, Z. Guo, C. Yang, F. Kong, W. Liu and A. Wang, J. Biotechnol., 2013, 168(2), 234-239.

21 W. Cai, W. Liu, J. Han and A. Wang, Biosens. Bioelectron., 2016, 80, 118-122.

22 W. Cai, T. Han, Z. Guo, C. Varrone, A. Wang and W. Liu, Bioresour. Technol., 2016, 208, 13-18.

23 W. Liu, W. Cai, Z. Guo, L. Wang, C. Yang, C. Varrone and A. Wang, Renewable Energy, 2016, 91, 334-339.

24 P. Parameswaran, H. Zhang, C. I. Torres, B. E. Rittmann and R. Krajmalnik-Brown, Biotechnol. Bioeng., 2010, 105, 69-78.

25 H. S. Lee and B. E. Rittmann, Environ. Sci. Technol., 2009, 44, 948-954.

26 D. J. Batstone, P. F. Pind and I. Angelidaki, Biotechnol. Bioeng., 2003, 84, 195-204.

27 M. Stieb and B. Schink, Arch. Microbiol., 1986, 144, 291-295.

28 G. Kyazze, A. Popov, R. Dinsdale, S. Esteves, F. Hawkes, G. Premier and A. Guwy, Int. J. Hydrogen Energy, 2010, 35, 7716-7722. 